This item was submitted to Loughborough's Research Repository by the author.

Items in Figshare are protected by copyright, with all rights reserved, unless otherwise indicated.

\title{
Sprint performance and propulsion asymmetries on an ergometer in trained high- and low-point wheelchair rugby players
}

PLEASE CITE THE PUBLISHED VERSION

https://doi.org/10.1111/sms.13056

PUBLISHER

Wiley

VERSION

AM (Accepted Manuscript)

\section{PUBLISHER STATEMENT}

This work is made available according to the conditions of the Creative Commons Attribution-NonCommercialNoDerivatives 4.0 International (CC BY-NC-ND 4.0) licence. Full details of this licence are available at: https://creativecommons.org/licenses/by-nc-nd/4.0/

\section{LICENCE}

CC BY-NC-ND 4.0

\section{REPOSITORY RECORD}

Goosey-Tolfrey, Vicky, Riemer J. Vegter, Barry Mason, Thomas A.W. Paulson, John P. Lenton, Jan W. Van Der Scheer, and Lucas H.V. van der Woude. 2019. "Sprint Performance and Propulsion Asymmetries on an Ergometer in Trained High- and Low-point Wheelchair Rugby Players". figshare. https://hdl.handle.net/2134/28111. 
1 Sprint performance and propulsion asymmetries on an ergometer in trained high- and 2 low-point wheelchair rugby players

3

4 Victoria L Goosey-Tolfrey ${ }^{1}$, Riemer J K Vegter ${ }^{2,3}$, Barry S Mason ${ }^{1}$, Thomas A W Paulson ${ }^{1}$,

5 John P Lenton ${ }^{1,4}$, Jan W van der Scheer ${ }^{1}$ and Lucas H V van der Woude ${ }^{2,3}$

6

$7 \quad{ }^{1}$ School for Sport, Exercise and Health Sciences, The Peter Harrison Centre for Disability 8 Sport, Loughborough University, United Kingdom.

$9 \quad{ }^{2}$ University of Groningen, University Medical Center Groningen, Center for Human Movement 10 Sciences, the Netherlands.

$11{ }^{3}$ University of Groningen, University Medical Center Groningen, Center for Rehabilitation, the

12 Netherlands.

$13{ }^{4}$ GBCT Para-Cycling, British Cycling, National Cycling Centre, Stuart Street, Manchester, 14 United Kingdom.

16 Corresponding author:

17 V.L. Goosey-Tolfrey

18 Email: V.L.Tolfrey@lboro.ac.uk

19 Tel: +44 (0)1509 226386

Running Head: Asymmetries in wheelchair sprinting 


\section{Abstract}

The purpose of this study was to examine the propulsion asymmetries of wheelchair athletes whilst sprinting on an instrumented, dual-roller ergometer system. Eighteen experienced wheelchair rugby players (8 low-point (LP) (class $\leq 1.5$ ) and 10 high-point (HP) (class $\geq 2.0$ )) performed a 15s sprint in their sports wheelchair on the instrumented ergometer. Asymmetry was defined as the difference in distance and power output (PO) between left and right sides when the best side reached $28 \mathrm{~m}$. Propulsion techniques were quantified based on torque and velocity data. HP players covered an average $3 \mathrm{~m}$ further than the LP players $(P=0.002)$ and achieved faster sprint times than LP players (6.95 \pm 0.89 vs. $8.03 \pm 0.68 \mathrm{~s}, P=0.005)$ and at the time the best player finished (5.96 s). Higher peak PO’s (667 \pm 108 vs. $357 \pm 78 \mathrm{~W}, P=0.0001$ ) and greater peak speeds were also evident were for HP players ( $4.80 \pm 0.71$ vs. $4.09 \pm 0.45$ $\left.\mathrm{m} \cdot \mathrm{s}^{-1}, P=0.011\right)$. Greater asymmetries were found in HP players for distance (1.86 $\pm 1.43 \mathrm{vs}$. $0.70 \pm 0.65 \mathrm{~m}, P=0.016)$, absolute peak PO $(P=0.049)$ and speed $(0.35 \pm 0.25$ vs. $0.11 \pm 0.10$ $\mathrm{m} \cdot \mathrm{s}^{-1}, P=0.009$ ). Although HP players had faster sprint times over $28 \mathrm{~m}$ (achieved by a higher PO), high standard deviations show the heterogeneity within the two groups (e.g. some LP players were better than HP players). Quantification of asymmetries is not only important for classifiers but also for sports practitioners wishing to improve performance as they could be addressed through training and/or wheelchair configuration.

41

Keywords: Tetraplegic; wheelchair propulsion; dual-roller system; Paralympic sport; asymmetry 


\section{Introduction}

Wheelchair rugby (WCR) is designed for individuals with both lower and upper limb impairments which includes players with a spinal cord injury (SCI) at the cervical region of the spinal cord (known as tetraplegia), cerebral palsy (CP), multiple amputations and neuromuscular disease (IWRF, 2016). Based on physical impairment, WCR players are classified into one of seven classification groups from 0.5 (most impaired) to 3.5 (least impaired) (IWRF, 2016) to minimise the impact of impairment on the outcomes of competition (Tweedy \& Vanlandewijck, 2011). Our understanding of the sport to date is that high-point (class 2.0-3.5; HP) players are able to execute greater peak speeds compared to low-point (0.51.5; LP) players (Rhodes et al., 2105a; Rhodes et al., 2015b). Moreover, time spent performing high-speed activities have been noted to be greater in HP compared to LP players (Rhodes et al., 2015a). Consequently, sprint performance is a key aspect of WCR, since accelerating faster than your opponent is essential to be free to catch the ball; preferably in the end zone (Malone \& Orr, 2010; van der Slikke et al., 2016).

Yet in-depth biomechanical analyses of sprint performances on court are difficult because instrumentation of the individually optimized wheelchair-user configuration requires high-end sensitive measurement techniques that might also alter an athlete's performance (Vanlandewijck et al. 2001; Mason et al. 2013). Therefore, instrumented dual-roller ergometers have been developed that allow measurement of power output (PO) in combination with acceleration, while importantly keeping the wheelchair-user combination unaltered (Devillard et al. 2001; Faupin et al., 2004). One clear difference with propelling on court however is the removal of a steering component while propelling on such a stationary device, allowing for differences in left-right performance without a consequent change in direction over ground. Interestingly, the assumption of whether wheelchair propulsion is considered a symmetric bimanual task has recently resurfaced during conditions of daily manual wheelchair 

et al. 2014; Soltau et al., 2015; Chénier et al. 2017). Although for a balanced wheelchair user combination the PO on average must be the same on both sides (i.e. symmetric) to propel in a straight line, how this power production comes about can differ between the left and right side and is almost never the same when comparing the left and right push cycle directly to each other (i.e. asymmetric).

Inherent to some of the WCR players' health conditions, differences in strength and coordination between the left and right side are expected (Soltau et al., 2015). Especially during a sprint at maximal intensity in which case one approaches the biophysical limits of performance including the bimanual motor control of this task. However, on court given the constraints of straight-line propulsion these differences cannot be well assessed since the most impaired arm inhibits the less impaired one to perform more power, which would result in a turn. There has been a reinstated interest in the measurement of short-term power during wheelchair propulsion with respect to resistive load (Hintzy et al., 2003), rear-wheel camber (Faupin et al., 2004) and propulsion modality (Faupin et al., 2013) using instrumented dualroller wheelchair ergometers (Devillard et al., 2001). However, these aforementioned studies have been limited to able-bodied female participants or wheelchair basketball players and have not necessarily examined asymmetries in bimanual PO, or the different wheelchair user interface of specialized sport chairs.

Despite the array of health conditions now eligible to play WCR only a few studies have examined the dynamic responses of WCR propulsion with respect to the HP and LP categories. For instance, some WCR players present an increased muscle tone or spasticity and impaired co-ordination leading to muscle imbalance and reduced muscle power (Paulson \& Goosey-Tolfrey, 2017). As far as push symmetry is concerned, symmetrical and synchronous 
has been shown to exist between upper arm coordination and technical efficiency (Faupin et al., 2013; Qi et al., 2013). These aforementioned studies, confirm the importance of push symmetry as a valuable performance indicator that has not been examined within the sport of WCR. Moreover, it is unknown as to whether asymmetries are more prevalent in HP players where there is potential for greater variation between arm scores than at the lower end of the classification system. Subsequently, the motor-coordination and PO of the left and right arms could be measured using the dual-roller wheelchair system. Therefore, the purpose of this study was to examine the sprint performance of experienced WCR players and to determine whether differences in asymmetries existed between HP or LP players.

\section{Materials and Methods}

Participants

Eighteen experienced WCR players (age $31 \pm 6$ yrs; body mass of $65.9 \pm 14.0 \mathrm{~kg}$ ) participated in this study. Diagnoses of physical disabilities met the eligibility criteria to participate in WCR: SCI of the cervical region $(n=12)$, cerebral palsy $(C P ; n=2)$, amputation (AMP; $n=1)$ and les autres (LA; n=3). In line with current WCR literature (Altmann, 2017; Rhodes et al. 2015a, 2015b) subgroups comprising of athletes classed according to the IWRF (IWRF, 2016) classifications as $\leq 1.5(\mathrm{n}=8)$ Low Point (LP) [6 SCI and 2 LA] and $\geq 2.0(\mathrm{n}=10)$ Mid-to-High Point (HP) [6 SCI, 2 CP, 1 AMP and 1 LA; consisting of 8 Mid and 2 High Point players] were formed.

Prerequisite for participation was prior experience in wheelchair sports and/or training at a national sporting level for $>10$ hours per week in WCR for a minimum of 4 years. For this reason, athletes had been advised on the optimisation of their WCR games chair (wheelchairuser interface; including whether wheelchair straps and/or an abdominal binder was used) and so had a reproducible acquired preference of arm movement frequency/ strategy for wheelchair 
propulsion. Body mass was recorded to the nearest $0.1 \mathrm{~kg}$ using a seated balance scale (Seca 710, Hamburg, Germany). The study was approved by the University Research Ethics Committee and all participants volunteered and provided written informed consent prior to participation.

\section{Wheelchair ergometer}

All participants were tested in their own individualised WCR sports chair using a friction braked instrumented wheelchair ergometer (VP100H TE, HEF Tecmachine ${ }^{\circledR}$, AndrezieuxBoutheon, France) which has been extensively detailed by Devillard et al. (2001) (Fig. 1). All players wore their usual gloves (with adhesive), strapping and some an abdominal binder as they would have when partaking in a competitive WCR game. Rear wheel tyre pressure was standardised to player's self-selected pressure, rear-wheel camber ranged from $16-20^{\circ}$ and wheel size from 24-25 inches. Since testing involved players individually optimized wheelchair-user combination, no individual adjustments relative to anthropometric measures of the participants were made. The wheelchair ergometer system comprised of two pairs of independent rollers and was equipped with two electromagnetic brakes (Type ZX, Friedrichshafen, Germany), which has the capabilities to produce a braking torque of $0 \mathrm{Nm}$ to $4 \mathrm{Nm}$, on both the left and right sides of the roller system. The roller system was calibrated prior to testing as described by Faupin et al. (2013) and prior to testing each participant performed a deceleration test to ensure equal resistance on each side of the rollers. The left and right rollers were independently capable of real time measuring velocity, torque and the angle of rotation at $100 \mathrm{~Hz}$.

\section{Testing protocol}

After a familiarisation period of 5 min self-paced propulsion, determination of individual residual torque (Tr)) were completed during five short practice coast-down sprints. For this, players completed four-five maximal pushes then leaned forward with their hands on their 
knees until the wheels came to a complete stop. Full details of this procedure have been described elsewhere (Faupin et al., 2013). In brief calculations of the individual Tr for both the left and right rollers allowed adjustments to be made to ensure equal resistance were applied on both sides. In line with current physiological assessments in our laboratory and Hutlzer et al. (1998), we kept the braking load to a Tr that was sport-specific and realistic to the wheelchair-user interface of WCR (proportional to the mass of the participant and chair combined which ranged 0.5-1.12 Nm). This was achieved by placing the rear wheels on the centre of the rolling element of each roller and strapping the front castor wheels down securely. Following a rest period of 3 min and some stretches, participants performed a 15s sprint from a stationary start on the wheelchair ergometer. A 15s sprint was chosen to ensure that at least $28 \mathrm{~m}$ which represents the playing court distance was covered by all participants. Verbal encouragement was provided throughout the trial and pacing was not encouraged. Participants did not receive any feedback about their propulsion technique and their trunk movements were not restricted.

Custom written Matlab algorithms were used to analyse relevant biomechanical parameters and all values were recorded separately for the two wheels (de Groot et al., 2017; Vegter et al., 2013b). Torque and velocity data were low-pass filtered with a recursive secondorder Butterworth filter (cut-off frequency $10 \mathrm{~Hz}$ ). The PO at each side was calculated from the measured torque $(\mathrm{M})$, wheel velocity $\left(\mathrm{v}_{\mathrm{w}}\right)$ and wheel radius $\left(\mathrm{r}_{\mathrm{w}}, 0.31 \mathrm{~m}\right)$ :

Power output $=\mathrm{M} \cdot \mathrm{v}_{\mathrm{w}} \cdot \mathrm{r}_{\mathrm{w}}{ }^{-1}$

Timing parameters of the propulsion technique were determined from the torque signal.

Push time was defined as the time that the hand exerted a positive torque on the hand rim. Push time and recovery time together represent the cycle time. The push time was also expressed as a percentage of the cycle time. Frequency was defined as the number of complete pushes over $28 \mathrm{~m}$ of the sprint divided by the time it took to reach $28 \mathrm{~m}$. The work per push cycle was 
calculated as the power integrated over the wheel rotation angle. The contact angle was calculated from the angular velocity and defined as the angle at the end of a push minus the angle at the start. Furthermore, peak values of velocity $\left(\mathrm{m} \cdot \mathrm{s}^{-1}\right)$ and PO $(\mathrm{W})$ were calculated, both over the entire sprint and over the first three cycles only. The acceleration was calculated by taking the derivative of velocity, while the velocity signal was integrated for calculating the distance. Asymmetry (m) was defined as the absolute difference between the distances (m) covered left and right when the best side reached $28 \mathrm{~m}$ (see Fig. 2 for an illustration and parameters calculated). E.g. in addition, the absolute differences in peak PO (W) and peak speed $(\mathrm{m} / \mathrm{s})$ between sides and their relative difference (\% of the peak on the fastest side) were used to further quantify the differences between sides.

\section{Statistical analyses}

The Statistical package for Social Sciences (SPSS, version 22; Chicago, IL, USA) was used for all statistical analyses. Means and standard deviations were computed for all variables and the average of the left and right side were used to compare between HP and LP players. The Shapiro-Wilk test showed that all outcomes were normally distributed. T-tests (unpaired) were used to compare the classification groups on relevant parameters. Statistical significance was set at $P<0.05$. Effect sizes were calculated according to the mean differences between groups (LP and HP) and the pooled standard deviations of these differences, adjusted for unequal groups. The magnitude of the effects were defined as trivial $(<0.2)$, small $(0.2-0.6)$, moderate (0.6-1.2), large (1.2-2.0) and very large $(>2.0)$ based on previous guidelines (Batterham \& Hopkins, 2006). 90\% confidence intervals (90\% CI) were also calculated to determine the range within which the true effect sizes existed.

Results 
Age and body mass distribution were similar in both groups (31 \pm 6 vs. $31 \pm 6$ yrs; $67.0 \pm 13.4$ vs. $64.6 \pm 15 \mathrm{~kg}$ for HP and LP respectively), also there was no significant difference in rolling resistance between groups $(0.93 \pm 0.13$ vs. $0.83 \pm 0.28 \mathrm{Nm}, P=0.22$ for $\mathrm{HP}$ and LP respectively). On average HP players were quicker over $28 \mathrm{~m}(P=0.005)$ and reached higher peak speeds PO’s over the whole sprint and after the first 3 pushes $(P \leq 0.011)$ than LP players (Table 1). At the time the quickest player finished, HP players had covered a greater distance (22.9 \pm 3.2 vs. $18.9 \pm 1.8 \mathrm{~m}, P=0.002$ ) (Fig. 3a) than LP players. Differences were noted between the two groups in propulsion technique when an all-out effort $15 \mathrm{~s}$ sprint was performed. During these sprints, it was shown that there was a significantly higher push frequency $(P=0.014)$ and work/push $(P=0.038)$ and a lower percentage push time $(P=0.009)$ for the HP players. In contrast, no differences in contact angle were found between groups (Table 1). The differences in propulsion technique when sprinting between the two players (HP and LP) are clearly shown in Fig. 4.

High-point players also demonstrated greater asymmetries (distances travelled (m) between the left and right sides ( $P=0.016)$; see Fig. $3 b)$, with a better symmetry evident for LP players. High-point players also demonstrated greater asymmetries in absolute peak PO $(P=$ 0.049), peak speed $(P=0.009)$ and peak speed after 3 cycles $(P=0.046)$. Although in relative terms (\% of peak) these were only greater for peak speed $(P=0.009)$. High-point players registered faster sprint times over $28 \mathrm{~m}$ (achieved as noted earlier by a higher PO leading to higher acceleration and consequently higher top speeds). Yet, high standard deviations show the heterogeneity within the two groups (e.g., some LP players were faster than HP players) (Fig. 3a).

\section{Discussion}

The aim of this research was to utilise a dual-roller ergometer system to assess the sprint performance and propulsion asymmetries of WCR players in their individually optimized 
sports wheelchair set-up. Given that acceleration of the wheelchair is considered to be one of the most important aspects of WCR game play (Malone \& Orr, 2010), then it is important to determine sprint performance differences between players. The peak speeds achieved after 3 pushes (3.76 \pm 0.47 and $3.20 \pm 0.30 \mathrm{~m} \cdot \mathrm{s}^{-1}$; HP and LP respectively) were similar to those values reported during International wheelchair game play of similar IWRF classes (Rhodes et al., 2015a; Rhodes et al., 2015b), demonstrating the trained status and experience of the present sample. As expected, HP players achieved $\sim 15 \%$ faster sprint times over $28 \mathrm{~m}$ than LP players (4.80 \pm 0.71 and $4.09 \pm 0.45 \mathrm{~m} \cdot \mathrm{s}^{-1}$ ), which were achieved by a higher peak PO (667 $\pm 108 \mathrm{vs}$. $357 \pm 78 \mathrm{~W}$ ), leading to higher acceleration and consequently higher top speeds. Yet, high standard deviations demonstrate the heterogeneity within the two groups and some LP players were faster than HP players. Training status and technical experience (Rhodes et al., 2015a), wheelchair configuration (e.g., wheel size, and/or camber) (Mason et al., 2013) to the functional abilities of the WCR player and total mass of the wheelchair-user combination (e.g., differences in rolling resistance and internal friction) were likely to have contributed to these differences in sprint performance. It is difficult to compare these values to other studies due to limited data on WCR players and also the fact that other wheelchair ergometer studies have restricted the maximal velocity to $\leq 3 \mathrm{~m} \cdot \mathrm{s}^{-1}$. That said, to the authors' knowledge this is the only study that has examined the sprint performance on a dual-roller ergometer of highly trained athletes who are eligible to compete in WCR.

As described earlier, competitive WCR game play allows players with tetraplegia, CP, multiple amputations and neuromuscular disease to compete together (IWRF, 2016). Previous work has shown asymmetries in the daily propulsion patterns of individuals with tetraplegia (Stephens \& Engsberg, 2010). The current study involved dynamic bouts of exercise ( 10 s) under conditions very different to those found during daily wheelchair ambulation. Not only do the wheelchair configurations of a sports vs. daily wheelchair differ (e.g., increased camber 
and wheel size), but during WCR sports propulsion the site of force transfer can occur at the wheel (e.g. tire) as opposed the hand-rim (Mason et al., 2009). To compensate for lack of hand function/grip, WCR players wear gloves and apply an adhesive to assist with this coupling and decoupling of the hand to the tire when applying forces on the wheels (Mason et al., 2009). All players in this study wore bespoke individualised gloves. As we investigated two distinct groupings of IWRF classifications, it is important to note that previous research has suggested that HP players tend to push the wheelchair with the palmar side of their hand, whereas LP players frequently switched to a backhanded technique and contact the hand-rims with the dorsal side of their hand (Mason et al., 2009). Asymmetries in propulsion parameters were observed and were exacerbated in HP players, possibly due to the greater upper extremity demands clearly evident by higher PO's in this group. Because WCR performance is related to both trunk and arm impairment (Altmann et al., 2017), further work is warranted to examine these asymmetries at an individual level using more detailed classification scores which are attainable via the classification process.

Quantification of these asymmetries is important, since addressing them through physical training, pre-habilitation exercises and/or wheelchair configuration could lead to better performance (Roeleveld et al., 1994; Requejo et al., 2008). Wheelchair fitting and configuration can have a significant effect on the mobility performance of wheelchair games players (Mason et al., 2013) and typically LP players who have reduced trunk function prefer a more posterior seat position (Haydon et al., 2016) to try to maximise their capabilities for greater acceleration. Whilst it was beyond the scope of this study to consider the individual's anthropometrics and wheelchair configurations, it was of interest to note that higher velocity combinations (i.e., shorter push and cycle times) were evident in the HP group. Moreover, after the first 3 pushes asymmetries were greater in HP in peak speed and even when these asymmetries were relative based on peak speed, they were still significantly greater in HP. That 
said, the side-to-side differences in PO warrants future study with respect to whether this occurred at the start of the sprint (e.g., problems with hand-to-tire coupling) or towards the end of the sprint (e.g., fatigue effects); whether the symmetry noted was due to the type of health condition (e.g., SCI vs. non-SCI) and/or whether there was asymmetric dynamic loading of the rollers. Nevertheless, the results of this study highlight the need to gather information on bilateral symmetry particularly if there are issues with secondary injury or pain (Stephens \& Engsberg, 2010; Soltau et al., 2015). It is also unknown at present whether WCR players would be at a higher risk of shoulder pain from these side-to-side asymmetries on the court or even whether these asymmetries exist during daily ambulation in day-chair wheelchair-user combinations. Consequently, these results are of interest to strength and conditioning practitioners as training regimes must address these side-to-side asymmetries alongside the tailored programmes that are often prescribed to develop the posterior muscle groups.

This work fills an important gap in the literature. A methodology for the assessment of push symmetry in wheelchair propulsion was developed. Yet by conducting the study we note that the asymmetries may have been related to a difference in arm scores between sides, which unfortunately was information unavailable at the time but has become a recent topic of interest by classifiers. From our practical experience differences between arms becomes more evident higher up the classification spectrum and could be the focus of future work within WCR.

While over-ground pushing is the most ecologically valid method (van der Slikke et al., 2015), this research comprised of the wheelchair-user combination with rolling resistances that allowed the wheelchair velocities that would be achieved on a WCR court to be reproduced on the dual-roller system. The use of a wheelchair ergometer does provide a controlled environment for data collection. The PO profiles were indicative for high performance WCR players, yet we must appreciate the many limitations of using a wheelchair ergometer vs. overground propulsion or treadmill exercise (Vanlandewijck et al., 2001; Mason et al., 2014). That 
said, the use of the instrumented dual-roller ergometer highlights that asymmetries do exist; and these data could become useful to assist with our understanding to support both classifiers as well as the strength and conditioning practitioners guidance given to WCR players.

The instrumented dual-roller ergometer enabled left and right asymmetries to be identified in experienced WCR players. The use of a 15s sprint seemed to be useful for the measurement of $28 \mathrm{~m}$ which is the length of a WCR court. As expected, HP players displayed faster sprint times, reached higher peak speeds and peak PO’s than LP players. That said, the HP players did not necessarily use a technique with fewer pushes to cover the $28 \mathrm{~m}$. Our results support the assumption that asymmetry exists when propelling under strenuous sport-like conditions and these were evident in the HP group that comprised of players with SCI and other health conditions. Quantification of these asymmetries are important not only for the classifier, but for the sports practitioner wishing to improve performance as they could be addressed through training and/or wheelchair configuration.

Acknowledgements

The authors would like to thank all the participants for taking part in the study and The Peter Harrison Centre for Disability Sport for their support.

310 Conflicts of interest

311 The authors declare no conflict of interest. 


\section{References}

1. Altmann VC, Groen BE, Hart AL, Vanlandewijck YC, van Limbeek J. The impact of trunk impairment on performance-determining activities in wheelchair rugby. Scand J Med Sci Sports 2017: 27(9):1005-1014.

2. Batterham AM, Hopkins WG. Making meaningful inferences about magnitudes. Int $J$ Sports Physiol Perform 2006: 1(1):50-57.

3. Chénier F, Malbequi J, Gagnon DH. Proposing a new index to quantify instantaneous symmetry during manual wheelchair propulsion. J Biomech 2017: 25:137-141.

4. de Groot S, Bos F, Koopman J, Hoekstra AE, Vegter RJK. Effect of holding a racket on propulsion technique of wheelchair tennis players. Scand J Med Sci Sports 2017: 27(9):918-924.

5. Devillard X, Calmels P, Sauvigent B, Denis C, Simard C, Gautheron V. Validation of a new ergometer adapted for all types of manual wheelchairs. Eur J Appl Physiol 2001: 85:479-85.

6. Faupin A, Borel B, Meyer C, Gorce P, Watelain E. Effects of synchronous versus asynchronous mode of propulsion on wheelchair basketball sprinting. Disabil Rehabil Assist Technol 2013: 8(6):496-501.

7. Faupin A, Campilo P, Weissland T, Gorce P, Thevenon A. The effects of rear-wheel camber on the mechanical parameters produced during the wheelchair sprinting of handibasketball athletes. J Rehabil Res Dev 2004:41(3B):421-428.

8. Goosey-Tolfrey VL, Leicht C, Lenton J, Diaper N, Mason B. The BASES Expert Statement on Assessment of Exercise Performance in Athletes with a Spinal Cord Injury. The Sport and Exercise Scientist 2003a: 37:8-9.

9. Goosey-Tolfrey VL, Leicht C. Field based testing of wheelchair athletes. Sports Med 2003b: 43(2):77-91. 
10. Goosey-Tolfrey VL, Moss AD. The velocity characteristics of wheelchair tennis players with and without the use of racquets. APAQ 2005: 22: 291-301.

11. Haydon DS, Pinder RA, Grimshaw PN, Robertson WSP. Elite wheelchair rugby: a quantitative analysis of chair configuration in Australia. Sports Eng 2016: 19:177.

12. Hintzy F, Tordi N, Predine E, Rouillon JD, Belli A. Force-velocity characteristics of upper limb extension during maximal wheelchair sprinting performed by healthy able-bodied females. J Sports Sci 2003: 21(11):921-926.

13. Hutlzer Y. Anaerobic fitness testing of wheelchair users. Sports Med 1998:25(2):101-113.

14. International Wheelchair Rugby Federation (IWRF). Retrieved April 1, 2016, from http://www.iwrf.com.

15. Janssen TW, van Oers CA, Hollander AP, Veeger HE, van der Woude LH. Isometric strength, sprint power, and aerobic power in individuals with a spinal cord injury. Med Sci Sports Exerc 1993: 25(7):863-870.

16. Malone L, Orr K. Wheelchair Rugby. In Goosey-Tolfrey V. (Ed.) Wheelchair Sport. Human Kinetics 2010: pp. 151-166.

17. Mason B, van der Woude LHV, Goosey-Tolfrey VL. The influence of glove type on mobility performance for wheelchair rugby players. Am J Phys Med Rehabil 2009: 88 (7): 559-570.

18. Mason B, van der Woude LH, Goosey-Tolfrey VL. The ergonomics of wheelchair configuration for optimal performance in the wheelchair court sports. Sports Med 2013: 43(1):23-38.

19. Mason BS, Lenton JP, Leicht CA, Goosey-Tolfrey VL. A physiological and biomechanical comparison of over-ground, treadmill and ergometer wheelchair propulsion. J of Sports Sci 2014:32(1):78-91. 
20. Mason BS, Rhodes J, Goosey-Tolfrey VL. Validity and reliability of an inertial sensor for wheelchair court sports performance. J of Appl Biomech 2014:30(2): 326-331.

21. Paulson TA, Goosey-Tolfrey VL. Current perspectives on profiling and enhancing wheelchair court-sport performance. Int J Sports Physiol Perform 2017: 12(3): 275-286.

22. Perrat B, Smith M, Rhodes J, Mason B, Goosey-Tolfrey VL. Quality assessment of an UWB positioning system for indoor wheelchair court sports. $J$ Sports Engineering and Technology 2015: 229(2): 81-91.

23. Qi L, Wakeling J, Grange S, and Ferguson-Pell M. Coordination patterns of shoulder muscles during level-ground and incline wheelchair propulsion. J of Rehabil Res Dev. 2013: 50(5): 651-662.

24. Requejo P, Mulroy SJ, Haubert LL, Perry J. Evidence-based strategies to preserve shoulder function in manual wheelchair users with spinal cord injury. Top Spinal Cord Inj Rehabil 2008:13(4):86-119.

25. Rhodes J, Mason B, Perrat B, Smith M, Goosey-Tolfrey V. The validity and reliability of a novel indoor player tracking system for use within wheelchair court sports. $J$ of Sports Sci 2014: 32(17) 1639-1649.

26. Rhodes J, Mason BS, Malone LA, Goosey-Tolfrey VL. Effect of team rank and player classification on activity profiles of elite wheelchair rugby players. J of Sports Sci 2015a: 33(19), 2070-2078.

27. Rhodes J, Mason BS, Perrat B, Smith MJ, Malone LA, Goosey-Tolfrey VL. Activity profiles of elite wheelchair rugby players during competition. Int J Sports Physiol Perform 2015b: 10(3), 318-324.

28. Roeleveld K, Lute E, Veeger D, Gwinn T, van der Woude L. Power output and technique of wheelchair athletes. APAQ 1994: 11, 71-85. 
29. Sarro KJ, Misuta MS, Burkett B, Malone LA, Barros RM. Tracking of wheelchair rugby players in the 2008 Demolition Derby trial. J Sports Sci 2010: 28(2):193-200.

30. Sindall P, Lenton JP, Cooper RA, Tolfrey K, Goosey-Tolfrey VL. Data logger device applicability for wheelchair tennis court-movement. J of Sports Sci 2015: 33(5):527-533.

31. Soltau SL, Slowik JS, Requejo PS, Mulroy SJ, Neptune RR. An investigation of bilateral symmetry during manual wheelchair propulsion. Front Bioeng Biotechnol 2015: 3:86.

32. Stephens CL, Engsberg JR. Comparison of overground and treadmill propulsion patterns of manual wheelchair users with tetraplegia. Disabil Rehabil Assist Technol 2010:5, 420427.

33. Tweedy SM, Vanlandewijck YC. International Paralympic Committee position stand background and scientific principles of classification in Paralympic Sport. Br J Sports Med 2011: 45(4): 259-69.

34. van der Slikke RM, Berger MA, Bregman DJ, Veeger HE. Opportunities for measuring wheelchair kinematics in match settings; reliability of a three inertial sensor configuration. J Biomech 2015: 48(12): 3398-3405.

35. van der Slikke, RM, Berger MA, Bregman D, Veeger, D. Push characteristics in wheelchair court sprinting. Procedia Eng 2016 147: 730-734.

36. van der Woude LH, Bakker WH, Elkhuizen JW, Veeger, HE, Gwinn T. Propulsion technique an anaerobic work capacity in elite wheelchair athletes: cross-sectional analysis. Am J Phys Med Rehabil 1998: 77(3):222-234.

37. Vanlandewijck Y, Theisen D, Daly D. Wheelchair propulsion biomechanics: implications for wheelchair sports. Sports Med 2001: 31(5):339-367.

38. Veeger HE, Lute EMC, Roeleveld, K, van der Woude LH, Differences in performance between trained and untrained subjects during a 30-s sprint test in a wheelchair ergometer. Eur J Appl Physiol 1992: 64:158-164. 
411 39. Veeger HE, van der Woude LH, Rozendal RH. A computerized wheelchair ergometer. Results of a comparison study. Scand J Rehabil Med 1992: 24(1), 17-23.

40. Vegter R, de Groot S, Lamoth C, Veeger D, van der Woude L. Initial skill acquisition of handrim wheelchair propulsion: a new perspective. IEE Trans Neural Syst Rehabil Eng 2014: 22, 104-113.

41. Vegter R, Lamoth CJ, de Groot S, Veeger DH, van der Woude LH. Variability in bimanual wheelchair propulsion: consistency of two instrumented wheels during handrim wheelchair propulsion on a motor driven treadmill. J Neuroeng Rehabil 2013: 10(1): 9. 
Figure 1. Experimental set-up.

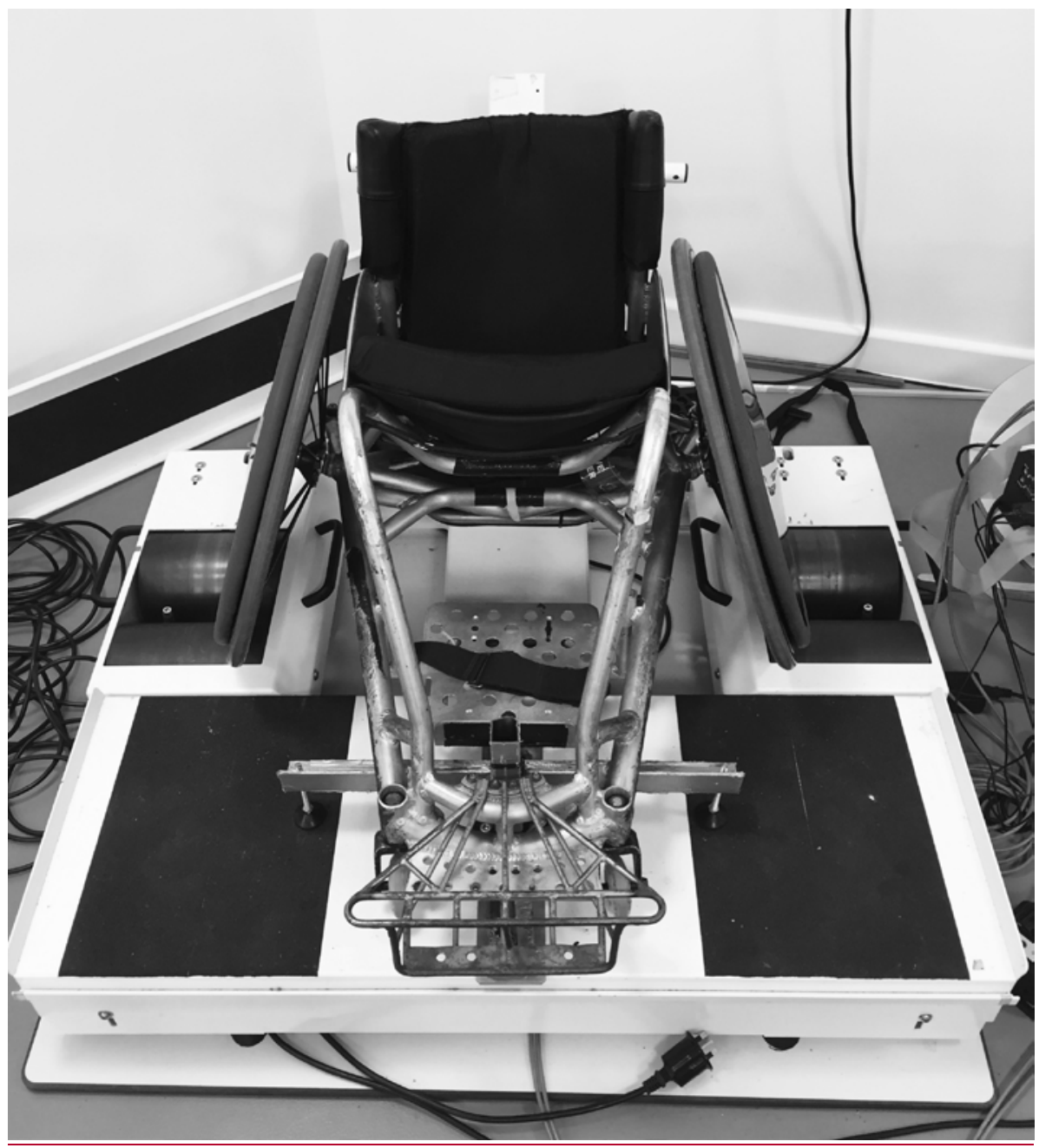

422 
443

444

445

446

447

448

449

Figure 2.Typical example of the pushes across time of the left and right side during the sprint of a high-point (HP) player (left graph) and a sprint of a low-point (LP) player (right graph) and corresponding distances covered. 

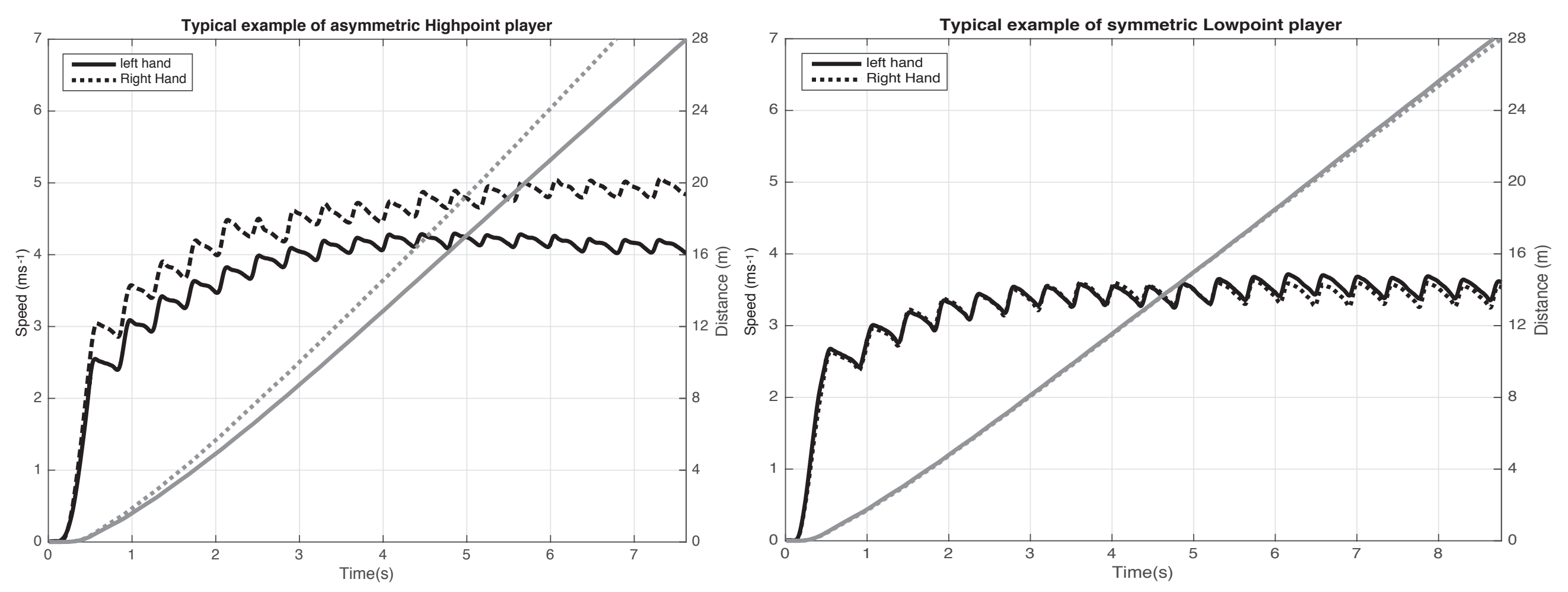
450 Figure 3. a) Individual distances covered by the wheelchair rugby players at the time the best player finished the $28 \mathrm{~m}$ sprint; b) An illustration of the asymmetries which was defined as the 452 difference between the distances achieved left and right when the best side reached $28 \mathrm{~m}$.

453

454

455

456

457

458

459

460

461

462

463

464

465

466

467

468

469

470

471

472

473

474 

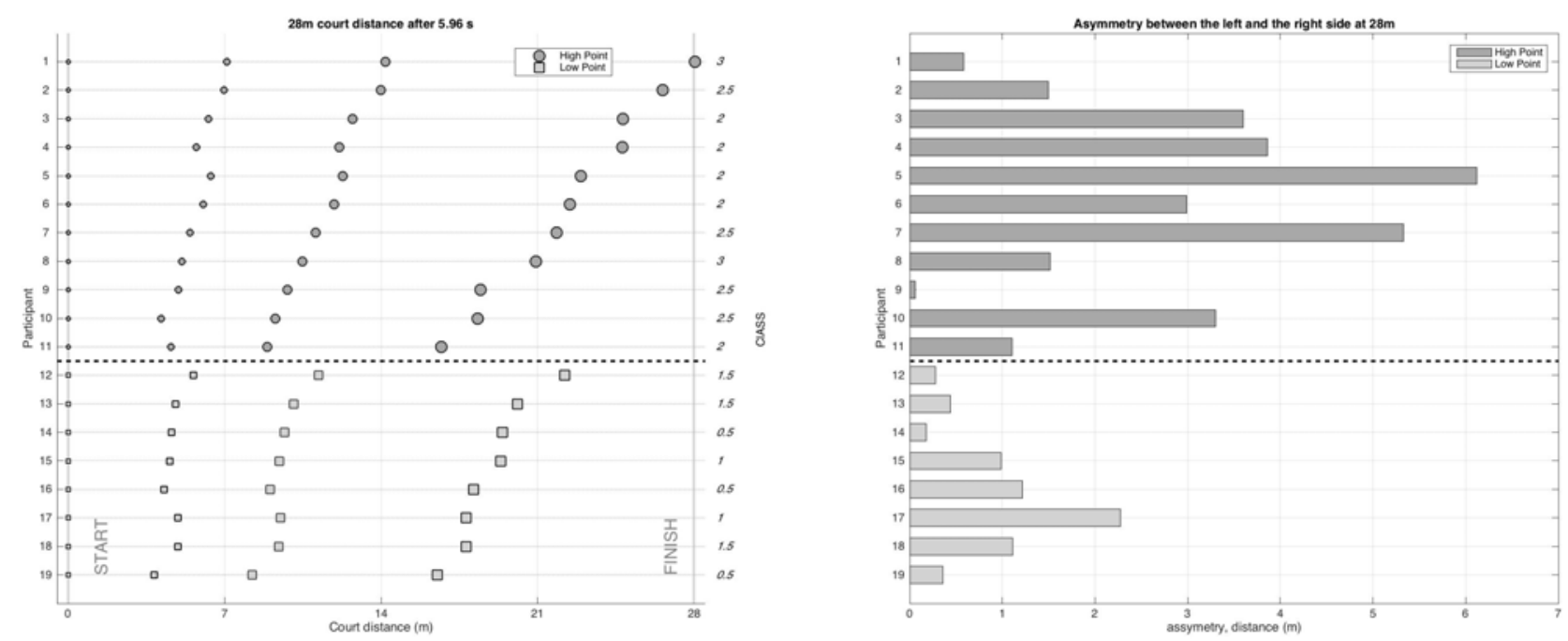
476 Figure 4: Typical example of the propulsion technique of the left and right side during the

477 sprint of a high-point (HP) player (upper graph) and a sprint of a low-point (LP) player (lower 478 graph).

479
480
481
482
483
484
485
486
487
488
489
490
491
492
493
494
495
496
497
499 

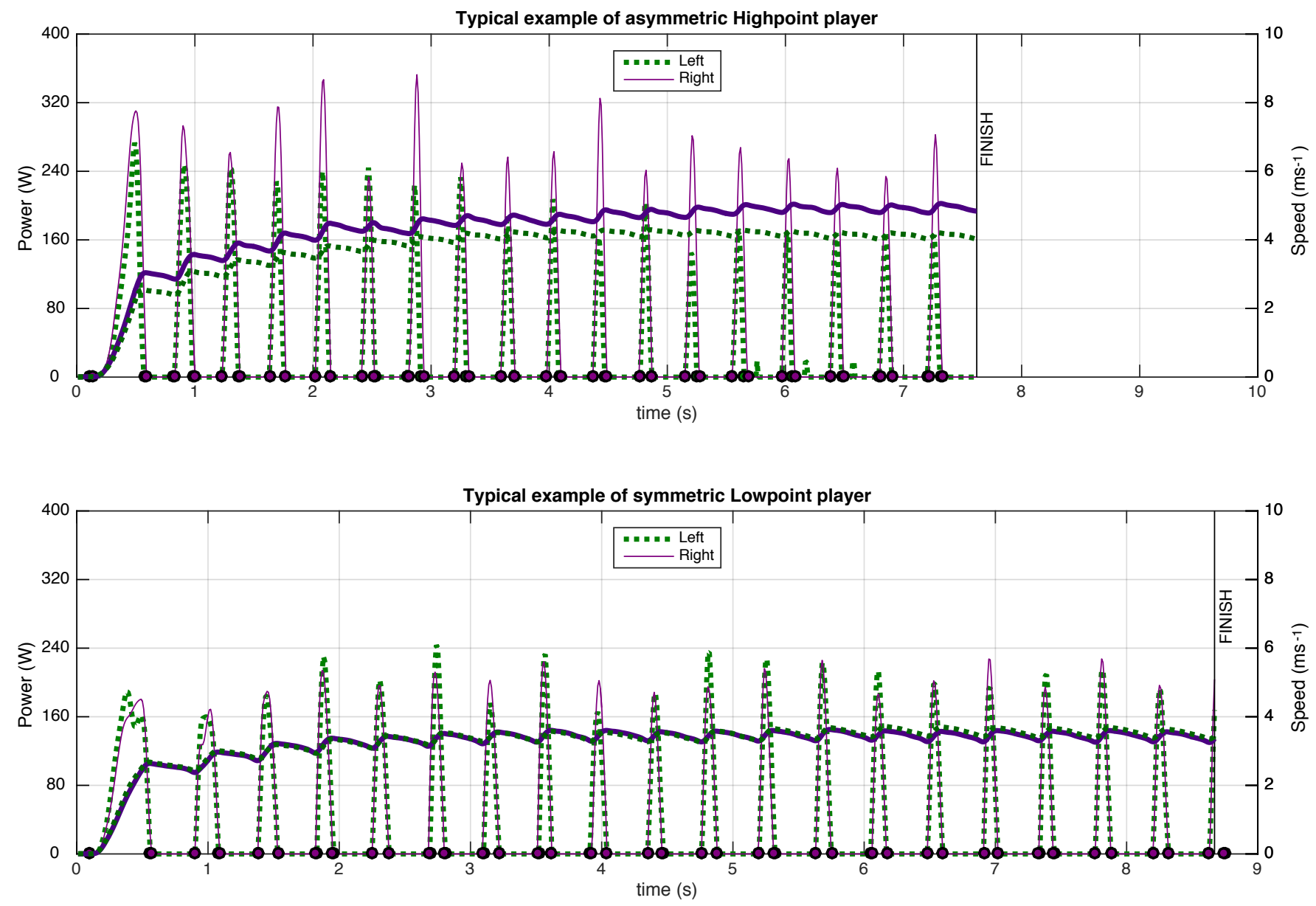
Tables

03

504

505 Table 1. Mean (standard deviation) of the propulsion technique variables (averaged left and

506 right) and asymmetries between sides for the different groups (HP and LP) of elite WCR

507 players

508

\begin{tabular}{|c|c|c|c|c|c|}
\hline & $\underline{\mathrm{HP}}$ & $\underline{\mathrm{LP}}$ & $\underline{P}$ & $\frac{\text { Effect size }}{( \pm 90 \% \mathrm{Cl})}$ & $\frac{\text { Qualitative }}{\text { outcome }}$ \\
\hline \multicolumn{6}{|l|}{ Grouped data: } \\
\hline Frequency $(\mathrm{Hz})$ & $\frac{2.56}{(0.31)}$ & $\frac{2.20}{(0.22)}$ & * & $\frac{1.30}{(0.46 \text { to } 2.14)}$ & Large \\
\hline Push time (\%) & $\frac{33.2}{(3.0)}$ & $\frac{38.1}{(4.4)}$ & $\underline{* *}$ & $\frac{1.35}{(0.50 \text { to } 2.19)}$ & Large \\
\hline Contact angle $\left({ }^{\circ}\right)$ & $\frac{95.8}{(19.2)}$ & $\frac{109.0}{(16.6)}$ & $\underline{N} . S$ & $\frac{0.73}{(-0.06 \text { to } 1.52)}$ & Moderate \\
\hline Work/push (J) & $\frac{19.5}{(5.2)}$ & $\frac{15.1}{(2.3)}$ & $\stackrel{*}{-}$ & $\frac{1.04}{(0.22 \text { to } 1.85)}$ & Moderate \\
\hline$\underline{28} \mathrm{~m}$ sprint time $(\mathrm{s})$ & $\frac{6.95}{(0.89)}$ & $\frac{8.03}{(0.68)}$ & $\underline{* *}$ & $\frac{1.33}{(0.49 \text { to } 2.18)}$ & Large \\
\hline Peak speed $(\mathrm{m} / \mathrm{s})$ & $\frac{4.80}{(0.71)}$ & $\frac{4.09}{(0.45)}$ & $\ddot{*}$ & $\frac{1.15}{(0.33 \text { to } 1.98)}$ & Moderate \\
\hline Peak speed after 3 cycles $(\mathrm{m} / \mathrm{s})$ & $\frac{3.76}{(0.47)}$ & $\frac{3.20}{(0.30)}$ & $* *$ & $\frac{1.37}{(0.52 \text { to } 2.22)}$ & $\underline{\text { Large }}$ \\
\hline Peak power (W) & $\frac{667}{(108)}$ & $\frac{357}{(78)}$ & $\underline{* *}$ & $\frac{3.20}{(2.60 \text { to } 4.35)}$ & Very large \\
\hline Peak power after 3 cycles (W) & $\frac{632}{(103)}$ & $\frac{343}{(67)}$ & $\underline{* *}$ & $\frac{3.21}{(2.07 \text { to } 4.36)}$ & Very large \\
\hline \multicolumn{6}{|l|}{ Asymmetries: } \\
\hline Distance $(\mathrm{m})$ & $\frac{1.86}{(1.43)}$ & $\frac{0.70}{(0.65)}$ & * & $\frac{0.99}{(0.18 \text { to } 1.80)}$ & Moderate \\
\hline Peak speed $(\mathrm{m} / \mathrm{s})$ & $\frac{0.35}{(0.25)}$ & $\underline{0.11}$ & $\underline{* *}$ & $\frac{1.21}{(0.36 \text { to } 2.06)}$ & $\underline{\text { Large }}$ \\
\hline Relative peak speed (\%) & $\frac{7.2}{(5.0)}$ & $\frac{2.5}{(2.2)}$ & $\underline{* *}$ & $\frac{1.17}{(0.33 \text { to } 2.01)}$ & Moderate \\
\hline Peak speed after 3 cycles $(\mathrm{m} / \mathrm{s})$ & $\underline{0.23}$ & $\underline{0.13}$ & * & $\underline{1.04}$ & Moderate \\
\hline
\end{tabular}




\begin{tabular}{|c|c|c|c|c|c|}
\hline & $(0.10)$ & $(0.09)$ & & $(0.21$ to 1.88$)$ & \\
\hline $\begin{array}{l}\text { Relative peak speed after } 3 \\
\text { cycles }(\%)\end{array}$ & $\frac{5.7}{(2.5)}$ & $\frac{3.9}{(2.4)}$ & $\underline{N} . S$ & $\frac{0.73}{(-0.07 \text { to } 1.54)}$ & Moderate \\
\hline Peak power (W) & $\underline{32.6}$ & $\frac{17.9}{(8.2)}$ & * & $\frac{0.78}{(-0.03 \text { to } 1.59)}$ & Moderate \\
\hline Relative peak power (\%) & $\frac{9.0}{(6.7)}$ & $\frac{9.2}{(4.4)}$ & $\underline{N} . S$ & $\frac{0.03}{(-0.75 \text { to } 0.82)}$ & $\underline{\text { Trivial }}$ \\
\hline Peak power after 3 cycles (W) & $\frac{27.6}{(17.5)}$ & $\frac{14.8}{(10.8)}$ & $\underline{N} . S$ & $\underline{0.86}$ & Moderate \\
\hline $\begin{array}{l}\text { Relative peak power after } 3 \\
\text { cycles }(\%)\end{array}$ & $\frac{8.3}{(5.4)}$ & $\frac{8.3}{(6.2)}$ & $\underline{N} . S$ & $\frac{\underline{0}}{(-0.78 \text { to } 0.78)}$ & $\underline{\text { Trivial }}$ \\
\hline
\end{tabular}

509

Note. $*=P<0.05, * *=P<0.01$ and N.S $=$ non-significant difference $(P>0.05)$ 